\title{
Comparison of oxycodone and morphine on the proliferation, apoptosis and expression of related molecules in the A549 human lung adenocarcinoma cell line
}

\author{
MI TIAN, LI JIN, RENQI LI, SIHAI ZHU, MUHUO JI and WEIYAN LI \\ Department of Anesthesiology, Jinling Hospital, School of Medicine, Nanjing University, Nanjing, Jiangsu 210002, P.R. China
}

Received February 18, 2015; Accepted October 13, 2015

DOI: $10.3892 / \mathrm{etm} .2016 .3346$

\begin{abstract}
The present study aimed to compare the effects of oxycodone and morphine hydrochloride on the proliferation, apoptosis and migration of A549 lung cancer cells. A549 human lung cancer cells were cultured in vitro and treated with oxycodone or morphine at various concentrations (10, 20 and $40 \mu \mathrm{g} / \mathrm{ml})$. Cell migration was determined using a wound healing assay, whereas apoptosis was detected using flow cytometry. Reverse transcription quantitative-polymerase chain reaction was performed in order to assess the apoptosis-related gene expression levels, including p53, B-cell lymphoma (Bcl)-2 and Bcl-2-associated $\mathrm{X}$ protein (Bax). The levels of vascular endothelial growth factor (VEGF) and urokinase-type plasminogen activator (uPA) were detected using enzyme-linked immunosorbent assays. The expression levels of intercellular cell adhesion molecule (ICAM)-1 were determined by immunofluorescence. In the present study, oxycodone and morphine induced apoptosis in A549 lung cancer cells with similar potency; however, $>20 \mu \mathrm{g} / \mathrm{ml}$ oxycodone was more effective at inhibiting cell proliferation $(\mathrm{P}<0.05)$ and migration $(\mathrm{P}<0.05)$, as compared with morphine at the same concentration. Oxycodone induced a dose-dependent increase in the expression levels of p53 and Bax apoptosis-related genes, whereas it decreased the gene expression levels of Bcl-2. Furthermore, oxycodone decreased, whereas morphine increased, the expression levels of ICAM-1 in a concentration-dependent manner. In addition, at $40 \mu \mathrm{g} / \mathrm{ml}$, the expression levels of VEGF and UPA in the morphine group were significantly higher than those demonstrated in the oxycodone group $(\mathrm{P}<0.05)$. In conclusion, oxycodone was more effective in inhibiting the proliferation and migration of A549 lung cancer cells, as compared with morphine.
\end{abstract}

Correspondence to: Dr Muhuo Ji or Dr Weiyan Li, Department of Anesthesiology, Jinling Hospital, School of Medicine, Nanjing University, 305 East Zhongshan Road, Nanjing, Jiangsu 210002, P.R. China

E-mail: jimuhuo2009@sina.com

E-mail: weiyanli1965@yahoo.com

Key words: oxycodone, morphine, lung adenocarcinoma cells, metastasis

\section{Introduction}

Despite recent advances in oncologic therapies, cancer remains a significant cause of morbidity and mortality worldwide (1). Lung cancer is the most common cancer worldwide, and non-small cell lung carcinoma accounts for $\sim 80 \%$ of all lung cancers (2). Surgical excision is the foundation of treatment for this type of cancer; however, metastatic disease is the most common cause of cancer-associated mortality (3-5).

It has previously been demonstrated that anesthetics and anesthesia techniques have an impact on the invasive and migratory ability of cancer cells, and may possibly affect the long-term prognosis of patients who have undergone cancer surgery (3). Pain management is a mandatory procedure in patients with cancer, since it improves the patient's quality of life and compliance to therapy (6). Opioids, particularly morphine, represent a mainstay of treatment for postoperative pain and for many types of chronic pain, including pain associated with cancer (6-8). However, previous studies have suggested that morphine analgesia may lead to a reduction in the activity and number of natural killer cells, which may weaken the immunologic barrier function and promote the differentiation of T helper (Th)1 lymphocytes into Th2 lymphocytes (9-11). Furthermore, previous preclinical data has suggested that morphine is proangiogenic and thus promotes cancer cell growth (12). One recent epidemiological study demonstrated that the replacement of postoperative opioids with epidural analgesia successfully reduced the risk of biochemical cancer recurrence following prostatectomy surgery, suggesting that opioids may favor cancer recurrence (13). Therefore, the selection of appropriate analgesics is vital in order to decrease the risk of metastasis and improve the quality of life of patients with cancer (14).

Oxycodone hydrochloride is a semi-synthetic opioid agent extracted from the alkaloid thebaine (15). The affinity of oxycodone hydrochloride for the $\mu$-opioid receptor is one-fifth to one-fortieth that of morphine, however, it is able to fully activate the $\kappa$-opioid receptor $(15,16)$. Although oxycodone possesses similar analgesic effects to morphine, its effects on the growth, apoptosis and migration of cancer are yet to be elucidated. The present in vitro study compared the effects of morphine and oxycodone on the proliferation, apoptosis and migration of the A549 human lung cancer cell line. 


\section{Materials and methods}

Methods. The A549 human lung cancer cell line was provided by the Department of Oncology, Jinling Hospital, Nanjing University (Nanjing, China). RPMI 1640 medium was purchased from HyClone Laboratories (GE Healthcare Life Sciences, Logan, UT, USA). Fetal calf serum (FCS), trypsin, penicillin and streptomycin were obtained from Gibco (Thermo Fisher Scientific Inc., Waltham, MA, USA). Oxycodone hydrochloride was purchased from Mundipharma Pharmaceutical Co., Ltd. (Cambridge, UK) and morphine hydrochloride was purchased from Shenyang First Pharmaceutical Factory of Northeast Pharmaceutical Group Co., Ltd. (Shenyang, China). The kits for apoptosis detection, human vascular endothelial growth factor (VEGF) and urokinase-type plasminogen activator (uPA) were purchased from Nanjing KeyGen Biotech Co., Ltd. (Nanjing, China). The PCR primers were synthesized by Invitrogen (Thermo Fisher Scientific Inc.) and the polymerase chain reaction (PCR) Master mix reagents were purchased from Promega Corporation (Madison, WI, USA). Intercellular cell adhesion molecule (ICAM)-1 antibody was purchased from Nanjing Dizhao Biological Technology Co., Ltd. (Nanjing, China).

Drug preparation. The oxycodone hydrochloride and morphine hydrochloride preparations were diluted to the desired concentrations with culture media under sterile conditions.

Cell culture. A549 cells were cultured in RPMI 1640 medium supplemented with $10 \% \mathrm{FCS}, 100 \mathrm{U} / \mu 1$ penicillin and $100 \mathrm{~g} / \mu 1$ streptomycin, and incubated at $37^{\circ} \mathrm{C}$ in an atmosphere containing $5 \% \mathrm{CO}_{2}$. Once the cells were confluent, they were digested with $0.25 \%$ trypsin and passaged in order to maintain cells in a logarithmic phase of growth. Cell proliferation was observed under an inverted microscope (Olympus Corporation, Tokyo, Japan) every $24 \mathrm{~h}$ and cells were routinely passaged every 2-3 days.

Methyl thiazolyl tetrazolium assay. The cells were digested and seeded in 96-well plates at a concentration of $1 \times 10^{5}$ cells $/ \mu 1$, with the exception of the outermost wells, which were filled with sterile saline solution. The cells were then washed twice with phosphate-buffered saline (PBS), and the study agents were diluted to the desired concentrations using culture solution and added to each well to a total volume of $100 \mu 1$. The control and blank control wells were set up and $15 \mu 1$ methyl thiazolyl tetrazolium solution ( $5 \mathrm{mg} / \mu \mathrm{l}$; Biocam GmbH, Berlin, Germany) was added to each well $48 \mathrm{~h}$ after adding the study drugs. The control well indicates the cells without adding the drug, while the blank control was exposed to culture solution only. After $4 \mathrm{~h}$, dimethyl sulfoxide $(150 \mu \mathrm{l})$ was added to each well, and the plate was agitated for $10 \mathrm{~min}$ in a shaker, in order to dissolve the crystals. Optical density (OD) was measured at $490 \mathrm{~nm}$ using the enzyme-linked immunosorbent assay method, and the cell inhibition rate was subsequently calculated for each treatment group.

Flow cytometry. Cell apoptosis was analyzed using an Annexin V-Fluorescein Isothiocyanate (FITC) Apoptosis
Detection kit (BD Pharmingen, San Diego, CA, USA), according to the manufacturer's protocol.

In the logarithmic growth phase, the A549 cells were seeded into 6 -well plates ( $2 \mu \mathrm{l} /$ well; $1 \times 10^{5}$ cells $\left./ \mu \mathrm{l}\right)$, cultured in an incubator for $24 \mathrm{~h}$ and the supernatant was discarded prior to the addition of the drug-containing media to the appropriate wells. Subsequently, the 6-well plate was incubated for $48 \mathrm{~h}$, and the cells were collected by digestion with trypsin. The cells were then washed twice with PBS, centrifuged at $375 \mathrm{x} g$ for $5 \mathrm{~min}$ and resuspended in $500 \mu \mathrm{l}$ binding buffer. A total of $5 \mu \mathrm{l}$ Annexin V-FITC was added and mixed into the cell suspension, followed by the addition of $5 \mu 1$ propidium iodide and subsequent mixing. The reaction was incubated for 5-15 min in a dark room. The early apoptotic cells were detected by flow cytometry within $1 \mathrm{~h}$.

Scratch assay. Lines were drawn on the back of a 6-well plate with a marker pen; the transverse lines were drawn uniformly at distances of $0.5-1 \mathrm{~cm}$ between the lines using a ruler, and the lines passed through the wells. Each well was subsequently inoculated with $\sim 5 \times 10^{5}$ cells, and vertical scratches perpendicular to the transverse lines on the underside of the plate were made the following day using a pen tip and a ruler. The cells were washed three times with PBS in order to remove the excess cell debris, in order to retain a clean wounding line. The plate was incubated at $37^{\circ} \mathrm{C}$ for $24 \mathrm{~h}$ in an atmosphere containing $5 \% \mathrm{CO}_{2}$, prior to sampling, and images were captured using a DSC-HX1 digital camera (Sony Corporation, Tokyo, Japan).

Reverse transcription ( $R T)$-PCR. A549 cells were treated with various concentrations of oxycodone and morphine, and subsequently cultured for $48 \mathrm{~h}$. cDNA was synthesized using a Takara Reverse Transcription kit (Clontech Laboratories, Inc., Mountain View, CA, USA) according to the manufacturer's protocol. Briefly, total RNA samples were isolated from human lung cancer cells (A549) using a Simply P Total RNA isolation Kit (BioFlux Corporation, Tokyo, Japan) according to the manufacturer's instructions. The quantity of total RNA was determined using an ND-1000 spectrophotometer (NanoDrop; Thermo Fisher Scientific, Wilmington, DE, USA) by measuring the optical density at A260 and A280 nm. Subsequently, the concentration of mRNA was adjusted to $1.0 \mathrm{~g} / \mathrm{ml}$. According to the manufacturer's protocol for the PCR Master Mix kit (Promega Corporation), $25 \mathrm{mg}$ reaction mixture was prepared in order to perform the PCR reaction. The cycling program was performed as follows: One cycle at $95^{\circ} \mathrm{C}$ for $5 \mathrm{~min} ; 32$ cycles of $95^{\circ} \mathrm{C}$ for $30 \mathrm{sec}, 55^{\circ} \mathrm{C}$ for $30 \mathrm{sec}$, $72^{\circ} \mathrm{C}$ for $45 \mathrm{sec}$; followed by a final elongation step at $72^{\circ} \mathrm{C}$ for 10 min, using a MultiGene Gradient PCR thermal cycler (Labnet International, Inc., Edison, NJ, USA). For p53, the forward primer was 5'-GAAACTACTTCCTGAAAACAA CGT-3' and the reverse was 5'-GCCTCACAACCTCCGTCA T-3', the amplicon size is 455 bp. For Bax, the forward primer was 5'-TTCTGACGGCAACTTCAACTG-3', and the reverse was 5'-TGAGGAGTCTCACCCAACCA-3', the amplicon size is $188 \mathrm{bp}$. For Bcl-2, the forward primer was 5'-GACGCT TTGCCACGGTGGTG-3', and the reverse was 5'-GGGGCA GGCATGTTGACTTCAC-3', the amplicon size is 356 bp. For $\beta$-actin, the forward primer was 5'-AACAAGATGAGATTG 

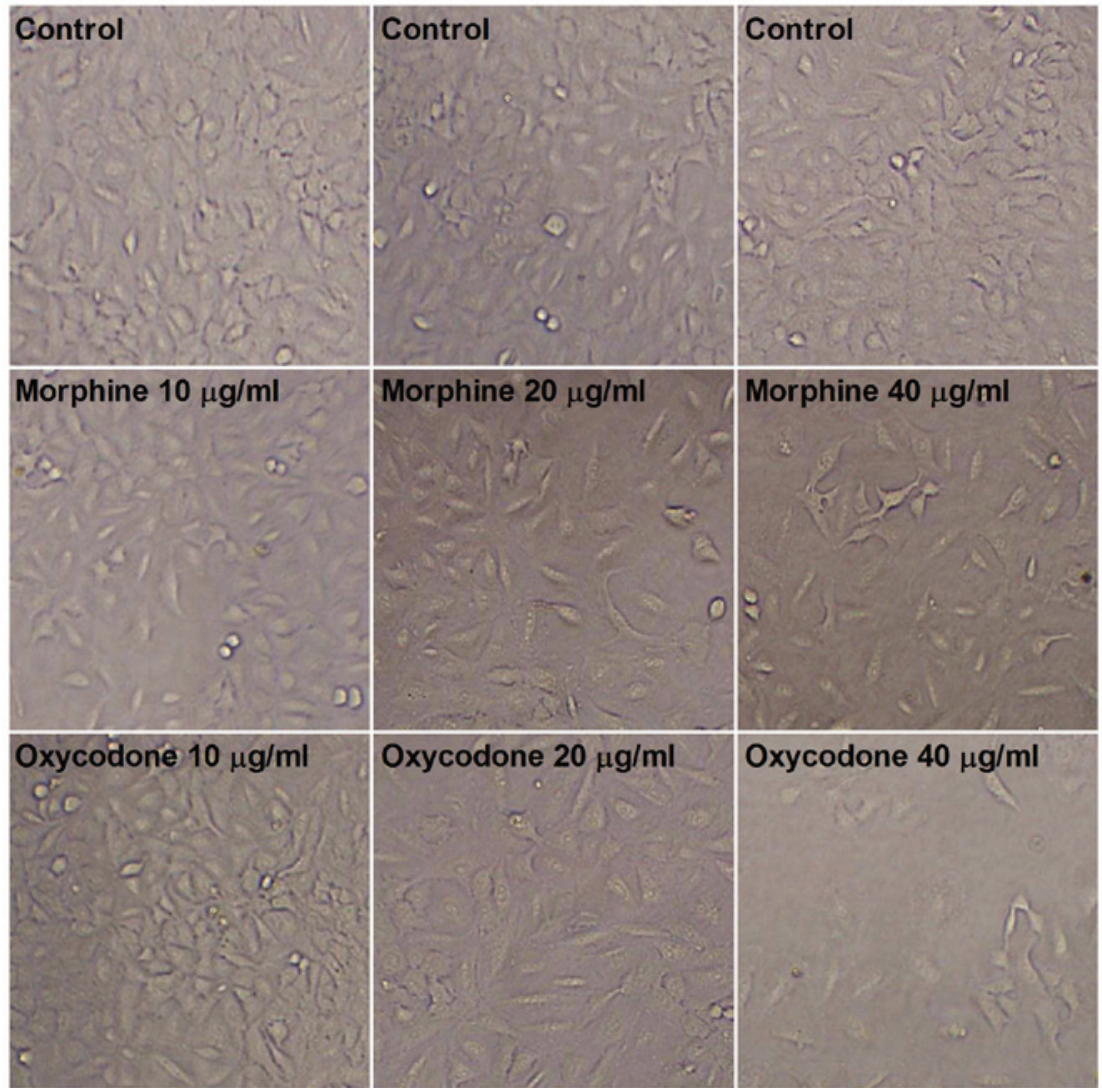

Figure 1. Effects of oxycodone and morphine administration on the morphology of the A549 human lung cancer cell line. Microscopic observation demonstrated that treatment with $40 \mu \mathrm{g} / \mathrm{ml}$ oxycodone or morphine induced typical apoptotic characteristics, including total atrophy and decreased cellular refractivity, with a more obvious inhibitory effect demonstrated following oxycodone administration (magnification, x100).

GCA-3', and the reverse was 5'-AGTGGGGTGGCTTTTAGG AT-3', the amplicon size is $251 \mathrm{bp}$. The $10 \mu \mathrm{l}$ PCR products were separated by electrophoresis on a $1.5 \%$ agarose gel, and images were captured using a Gel Doc XR gel-imaging system (Bio-Rad Laboratories, Inc., Hercules, CA, USA). The experiment was repeated three times. The mean grayscale values of the electrophoretic bands were analyzed using Quantity One 4.4.0 software (Bio-Rad Laboratories, Inc.).

Enzyme-linked immunosorbent assay. The cells were washed with PBS solution, the lysis buffer (Beyotime Biotech, Jiangsu, China) was added and the cell mixture was pipetted up and down several times. Following complete pyrolysis, the mixture was centrifuged at $14,000 \mathrm{xg}$ for $5 \mathrm{~min}$, and the supernatant was retained. The samples were prepared as follows: i) Blank wells, the blank control wells contained chromogenic reagents $\mathrm{A}$ and $\mathrm{B}$ and stop solution, and the operation steps were consistent with the other treatments; ii) testing sample wells, $100 \mu \mathrm{l}$ cell culture supernatant was added and incubated at $37^{\circ} \mathrm{C}$ for $90 \mathrm{~min}$ prior to the addition of $100 \mu \mathrm{l}$ biotin-labeled anti-uPA (1:100; SCS415Hu) and VEGF (1:100; SEA150Hu) antibodies (Dizhao Co., Ltd, Nanjing, China), which were incubated at $37^{\circ} \mathrm{C}$ for $60 \mathrm{~min}$. Following washing three times, $100 \mu 1$ horseradish peroxidase (HRP)-conjugated streptavidin secondary antibody was added to each well, and the plate was covered with a microplate sealer, gently shaken and incubated at $37^{\circ} \mathrm{C}$ for $30 \mathrm{~min}$; and iii) standard wells, $100 \mu \mathrm{l}$ standard substance was added

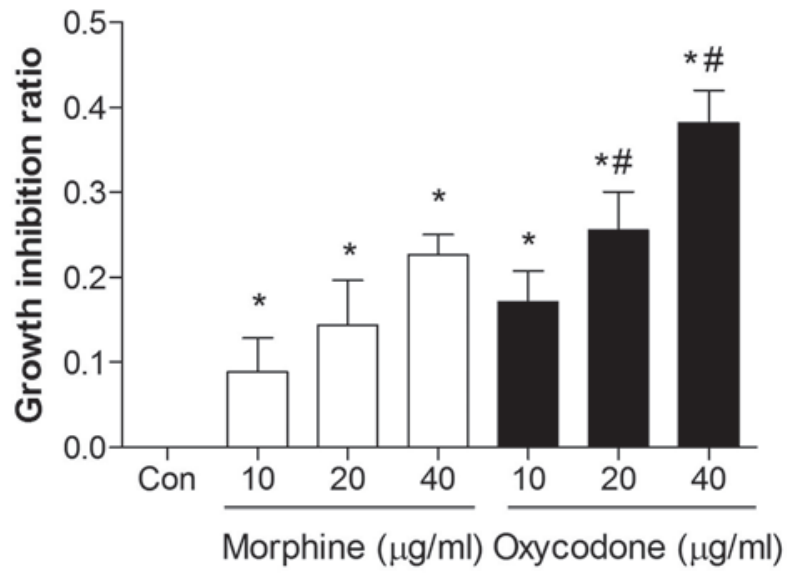

Figure 2. Effects of oxycodone and morphine administration on the proliferation of A549 cells. The proliferation of A549 cells was significantly inhibited following treatment with oxycodone or morphine, respectively, and both agents demonstrated a dose-dependent inhibitory effect. At concentrations $>20 \mu \mathrm{g} / \mathrm{ml}$, the inhibitory effects of oxycodone were more pronounced, as compared with morphine. Data are presented as the mean \pm standard error of the mean; ${ }^{*} \mathrm{P}<0.05$ vs. the control presented; ${ }^{\#} \mathrm{P}<0.05$ vs. the morphine groups at the corresponding concentrations $(n=6)$.

and incubated at $37^{\circ} \mathrm{C}$ for $90 \mathrm{~min}$, following this no washing was performed and $100 \mu \mathrm{l}$ biotin-labeled anti-uPA antibodies were subsequently added to the wells, and the plate was incubated at $37^{\circ} \mathrm{C}$ for $60 \mathrm{~min}$. The wells were washed three times, $100 \mu 1 \mathrm{HRP}-$ conjugated streptavidin was added, the plate was 

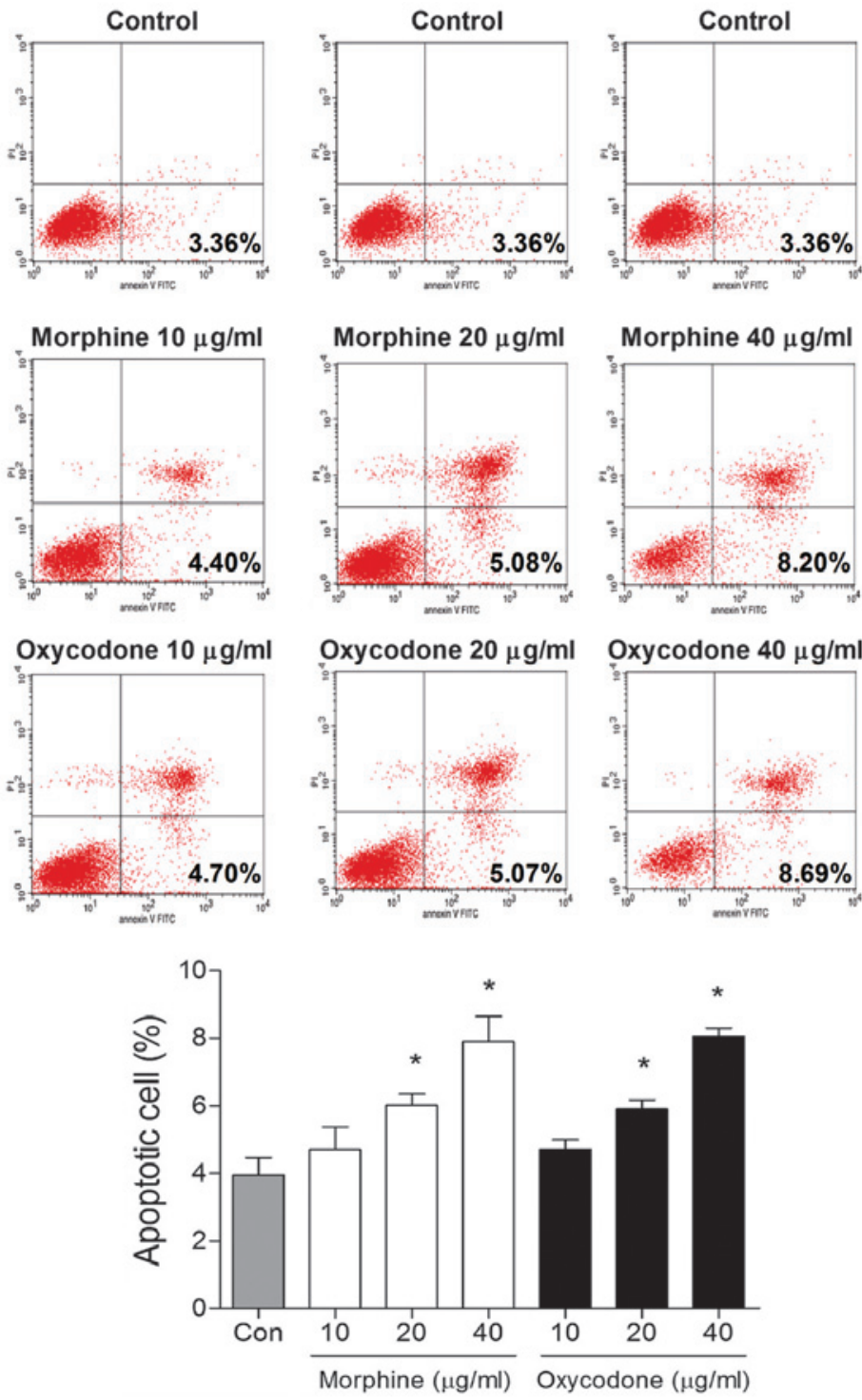

Figure 3. Effects of oxycodone and morphine administration on the apoptosis of A549 cells. Flow cytometry demonstrated no differences in the early apoptosis rates $48 \mathrm{~h}$ after the treatment of A549 cells with $10 \mu \mathrm{g} / \mathrm{ml}$ oxycodone or morphine, as compared with the control group (P>0.05). However, oxycodone/morphine treatment at the concentrations of 20 or $40 \mu \mathrm{g} / \mathrm{ml}$ significantly promoted apoptosis. Data are presented as the mean \pm standard error of the mean. "P $<0.05$ vs. the control group $(\mathrm{n}=5)$.

covered with a microplate sealer and gently shaken, and incubated at $37^{\circ} \mathrm{C}$ for $30 \mathrm{~min}$. Following this, $50 \mu \mathrm{l}$ chromogenic reagents $\mathrm{A}$ and $\mathrm{B}$ was added to each well and the plate was shaken gently and placed in the dark at $37^{\circ} \mathrm{C}$ for 15 -min color development. To terminate the reaction, $100 \mu 1$ stop solution was added to each well. A blank well was taken as zero, and the OD of each well was successively measured at $450 \mathrm{~nm}$ within $10 \mathrm{~min}$ of administering the stop solution, using a microplate reader (Bio-Rad Laboratories, Inc.). The standard curve and the concentrations of uPA and VEGF were calculated according to the concentration and the corresponding OD value of the standard wells.

Immunofluorescence. Cells were seeded into six-well plates with a $22 \times 22 \mathrm{~cm}$ coverslip. The following day, when the cells had adhered to the walls, the cells were fixed with $4 \%$ paraformaldehyde and washed three times with PBS. Following this, Triton X-100 (0.2\%-0.5\% in PBS) was used to permeabilize the cells for $10 \mathrm{~min}$, prior to washing three times with PBS. Subsequently, the cells were blocked with $2 \%$ bovine serum albumin for $30 \mathrm{~min}$, washed twice with PBS and incubated with primary antibodies at room temperature for $1 \mathrm{~h}$. Following washing three times with PBS, the cells were incubated with secondary antibodies for 30-40 min at room temperature and subsequently washed with PBS four times . ICAM-1 $(0.5 \mu \mathrm{g} / \mu \mathrm{l})$ was then added to the cells and incubated for $10 \mathrm{~min}$ prior to washing three times with PBS. Finally, the cells were mounted with $20 \mu 1$ mounting medium and observed using an Axio Observer A1 microscope (Carl Zeiss AG, Oberkochen, Germany).

Statistical analysis. Data analysis was performed using SPSS software (version 16.0; SPSS, Inc., Chicago, IL, USA). Statistical analysis was performed using analysis of variance followed by Tukey's test for individual comparisons between group means. Data are presented as the mean \pm standard error 


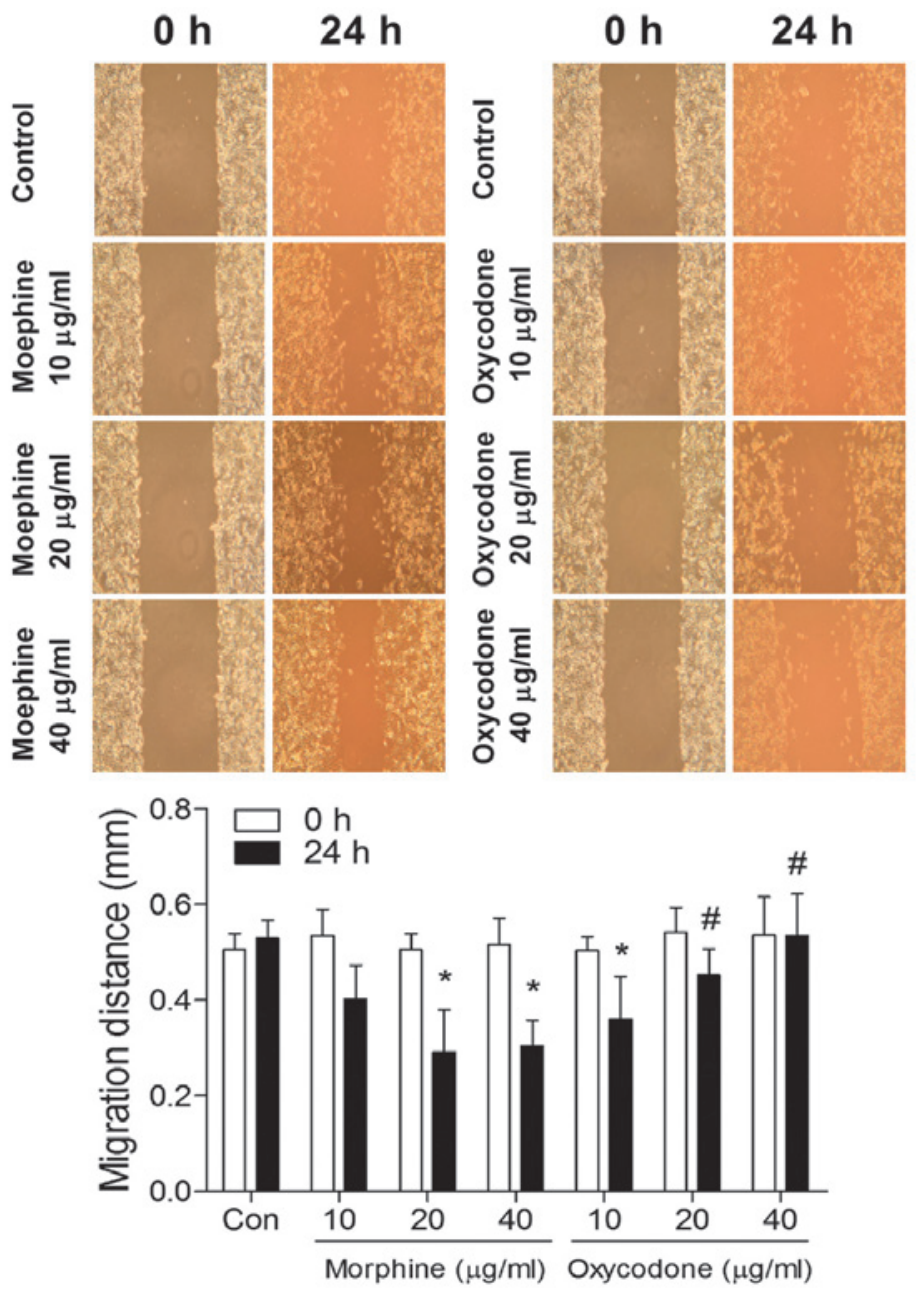

Figure 4. Effects of oxycodone and morphine administration on the migratory ability of A549 cells at $24 \mathrm{~h}$ (magnification, $\mathrm{x} 4$ ). The scratch assay demonstrated that treatment with morphine enhanced the migratory ability of the A549 lung cancer cells; whereas oxycodone treatment significantly decreased migratory ability. Data are presented as the mean \pm standard error of the mean, ${ }^{"} \mathrm{P}<0.05 \mathrm{vs}$. the control group; ${ }^{*} \mathrm{P}<0.05$ vs. the morphine groups at the corresponding concentration $(\mathrm{n}=6)$.

of the mean. $\mathrm{P}<0.05$ was considered to indicate a statistically significant difference.

\section{Results}

Effects of oxycodone and morphine on the cell morphology of the A549 human lung cancer cell line. As shown in Fig. 1, microscopic observation of the A549 cells in the control group demonstrated that they were uniform in size and grew adherently with a fusiform shape. Following treatment with oxycodone and morphine, the morphology of the A549 cells altered; the cells were no longer uniform size and exhibited irregular contours. Furthermore, the cells exhibited typical apoptotic characteristics, including total atrophy and decreased cellular refractivity following treatment with $40 \mu \mathrm{g} / \mathrm{ml}$ oxycodone or morphine, with a more obvious inhibitory effect demonstrated following oxycodone administration.

Effects of oxycodone and morphine on the proliferation of A549 cells. The proliferation of A549 cells was significantly inhibited following treatment with oxycodone or morphine, and both agents demonstrated a significant inhibitory effect $(\mathrm{P}<0.05)$ in a dose-dependent manner (Fig. 2).
Furthermore, when the concentrations were $>20 \mu \mathrm{g} / \mathrm{ml}$ the inhibitory effects of oxycodone were increased, as compared with morphine administration $(\mathrm{P}<0.05)$.

Effects of oxycodone and morphine on the apoptosis of A549 cells. Following treatment with $10 \mu \mathrm{g} / \mathrm{ml}$ oxycodone or morphine, no differences in the rates of early apoptosis were demonstrated after $48 \mathrm{~h}$, as compared with the control group ( $\mathrm{P}>0.05$; Fig. 3). However, oxycodone or morphine treatment was able to significantly promote apoptosis when the concentrations were $>20 \mu \mathrm{g} / \mathrm{ml}(\mathrm{P}<0.05)$.

Effects of oxycodone and morphine on the migratory ability of A549 cells at $24 \mathrm{~h}$. As outlined in Fig. 4, the scratch assay suggested that morphine may significantly increase $(\mathrm{P}<0.05)$ the migratory ability of A549 lung cancer cells in a dose-dependent manner; whereas the migratory abilities of the A549 lung cancer cells in the oxycodone group were significantly decreased $(\mathrm{P}<0.05)$ in a dose-dependent manner. Furthermore, when the concentrations were $>20 \mu \mathrm{g} / \mathrm{ml}$, the migration distances were significantly greater in the oxycodone groups, as compared with the morphine groups $(\mathrm{P}<0.05)$. 

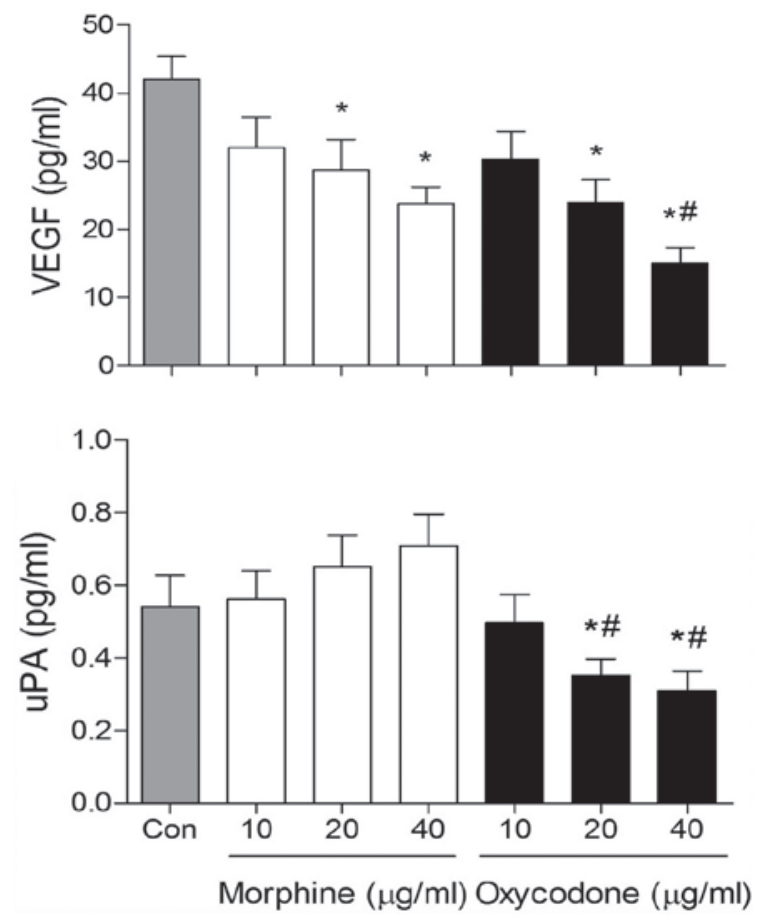

Figure 5. Effects of oxycodone and morphine administration on the expression levels of human vascular endothelial growth factor (VEGF) and urokinase-type plasminogen activator (uPA) in A549 lung cancer cells. As compared with the control group, the expression levels of VEGF and UPA in the morphine and oxycodone groups were decreased at concentrations of 20 or $40 \mu \mathrm{g} / \mathrm{ml}$. Furthermore, the expression levels of VEGF and uPA in the oxycodone group were significantly reduced at $40 \mu \mathrm{g} / \mathrm{ml}$, as compared with the morphine group. Data are presented as the mean \pm standard error of the mean. ${ }^{*} \mathrm{P}<0.05$ vs. the control group; ${ }^{"} \mathrm{P}<0.05$ vs. the morphine groups at the corresponding concentrations $(n=6)$.

Effects of oxycodone and morphine on the expression levels of VEGF and UPA in A549 cells. VEGF expression levels in the morphine and oxycodone groups were significantly decreased $(\mathrm{P}<0.05)$, as compared with the control group (Fig. 5). Furthermore, at the concentrations of $40 \mu \mathrm{g} / \mathrm{ml}$, the expression levels of VEGF were reduced in the oxycodone group, as compared with the morphine group $(\mathrm{P}<0.05)$. In addition, oxycodone downregulated the expression levels of uPA, whereas morphine upregulated uPA expression levels in A549 cells.

Effects of oxycodone and morphine on the expression levels of apoptosis-related mRNA in A549 cells. RT-PCR analysis demonstrated that the expression levels of B-cell lymphoma $(\mathrm{Bcl})-2$ were significantly decreased $(\mathrm{P}<0.05)$ in the oxycodone and morphine groups, whereas the expression levels of $\mathrm{p} 53$ and $\mathrm{Bcl}-2$-associated $\mathrm{X}$ protein (Bax) were significantly increased $(\mathrm{P}<0.05)$, as compared with the control group (Fig. 6). No differences were demonstrated between the effects of oxycodone and morphine when applied at equal concentrations.

Effects of oxycodone and morphine on the expression levels of ICAM-1 in A549 cells. Immunofluorescence analysis demonstrated that the fluorescence intensity of ICAM-1 gradually decreased with increasing oxycodone concentrations; whereas morphine induced a dose-dependent increase in the fluorescence intensity of ICAM-1 (P<0.05; Fig. 7).
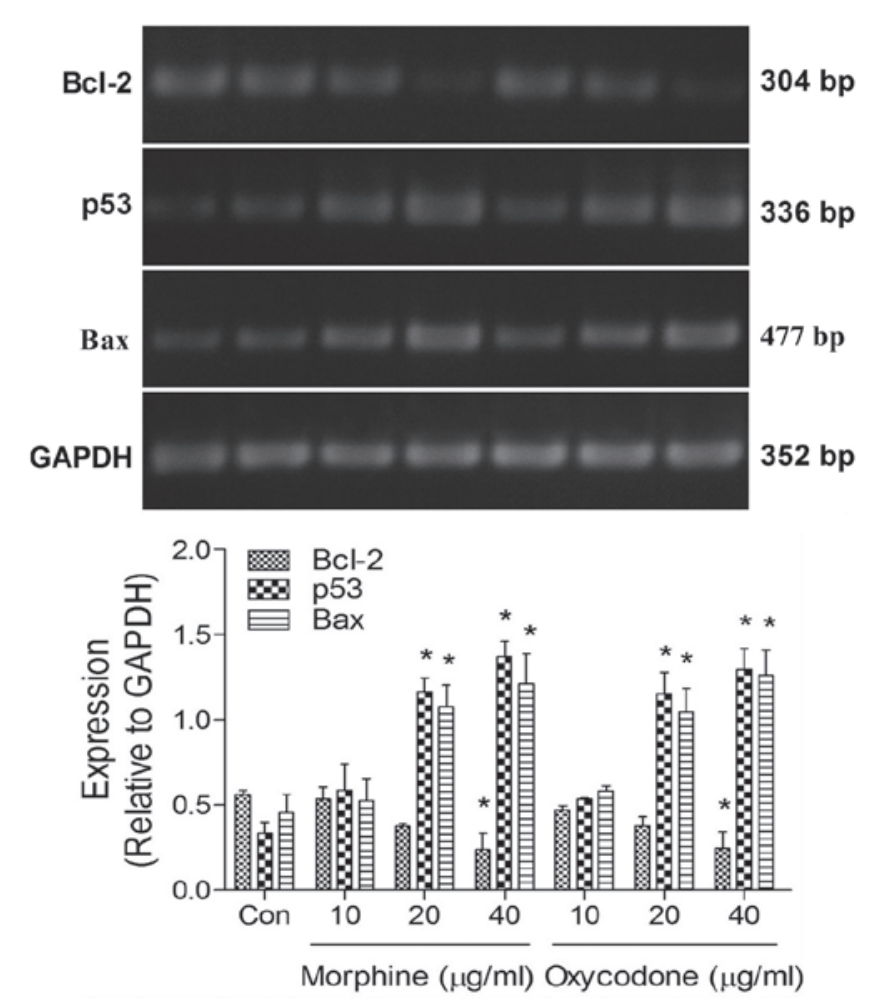

Figure 6. Effects of oxycodone and morphine on the mRNA expression levels of apoptosis-related proteins in A549 cells. Reverse transcription-polymerase chain reaction analysis demonstrated that the expression levels of B-cell lymphoma (Bcl)-2 were significantly decreased in the oxycodone and morphine groups; whereas p53 and Bcl-2-associated X protein (Bax) levels were significantly increased, as compared with the control group. Data are presented as the mean \pm the standard error of the mean. ${ }^{*} \mathrm{P}<0.05$ vs. the control group $(n=4)$.

\section{Discussion}

The present study demonstrated that oxycodone is capable of inhibiting the proliferation of A549 cells, inducing apoptosis, and weakening the invasive ability of A549 cells. These findings support the hypothesis that oxycodone may exert these effects on A549 tumor cells by modulating the expression levels of p53, Bax, Bcl-2, VEGF, ICAM-1 and uPA.

Previous studies have demonstrated that chemical mediators are released in response to surgical stress, which may upregulate malignant pathways and promote the recurrence of cancer $(4,5)$. Adequate pain management is essential in patients with cancer, in order to reduce immune deficiency against cancer recurrence and/or the spread of residual cancer cells promoted by surgical stress (17). However, opioids have also been demonstrated to promote cancer recurrence or progression by affecting the immune system or cancer cells (18). Opioid receptors are expressed in cancer cells (19) and opioids are capable of regulating the growth, proliferation and/or apoptosis of cancer cells by directly activating the respective receptors (20). Previous studies have suggested that anesthetics may have negative effects on the outcome of postoperative cancer recurrence by: Inducing molecular changes in cancer cells; modulating proliferation, angiogenesis and apoptosis; and exacerbating immunosuppression in patients with cancer undergoing surgery (3-6). Therefore, inhibition of the invasive and migratory potential of cancer cells may 

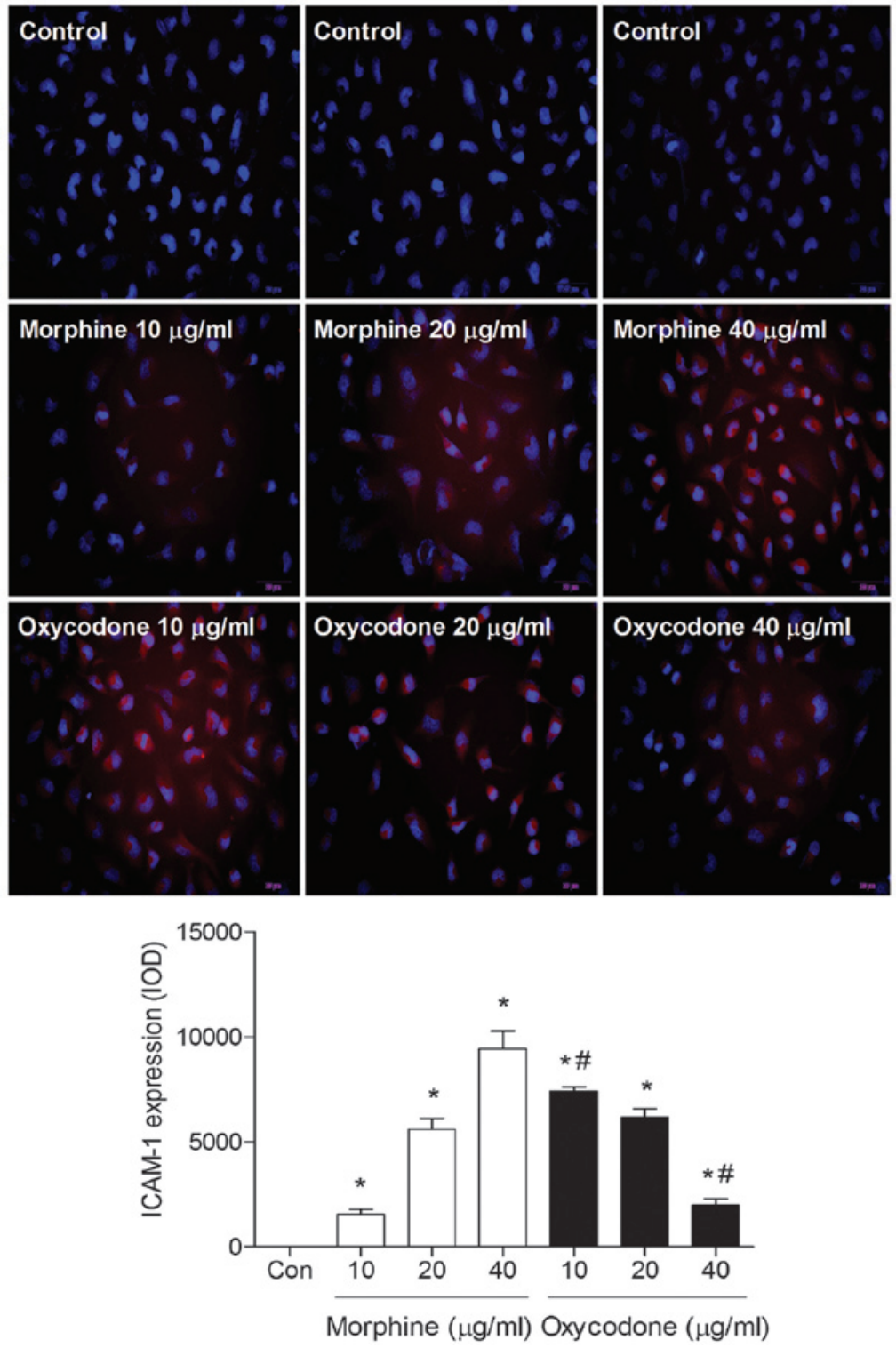

Figure 7. Effects of oxycodone and morphine on the expression levels of intercellular cell adhesion molecule (ICAM)-1 in A549 cells (magnification, x100). Immunofluorescence analysis demonstrated that fluorescence intensity gradually decreased as oxycodone concentration increased; however, morphine increased the fluorescence intensity in a dose-dependent manner, as compared with the control group. Data are presented as the mean \pm standard error of the mean. ${ }^{*} \mathrm{P}<0.05$ vs. the control group; ${ }^{\#} \mathrm{P}<0.05$ vs. the morphine groups at the indicated concentrations $(\mathrm{n}=5)$.

improve the outcome of cancer treatment. Mitigation of the metastatic potential of cancer cells during the perioperative period is a challenging topic for anesthesiologists. In the present study, oxycodone, which is a semi-synthetic opioid, significantly suppressed the invasion and migration of A549 cells. Furthermore, oxycodone and morphine successfully inhibited the growth of A549 cells. This corroborates the findings of a previous study, which demonstrated that $>10 \mu \mathrm{M}$ morphine inhibited the growth of SH-SY5Y cancer cells (21). Opioids are capable of stimulating the production and release of nitric oxide and reactive oxygen species, which may explain the anti-cancer effects of oxycodone and morphine $(22,23)$. However, a previous study has demonstrated that, at clinically relevant doses, morphine is capable of promoting neovascularization in a human breast tumor xenograft model in mice (12). These findings suggested that the effects of morphine on cancer cells may be dependent on concentration, cell-type specificity and the administration methods.

The proliferation of cancer cells depends on numerous factors, with angiogenesis of particular importance. It is well established that VEGF regulates angiogenesis (12). The results of the present study demonstrated that, at higher concentrations $(40 \mu \mathrm{g} / \mathrm{ml})$, oxycodone decreased the expression levels of VEGF in A549 cells more profoundly than morphine was able to. Notably, Gupta et al observed that morphine at concentrations observed in a patient's blood may cause the opposite effect, resulting in the stimulation of angiogenesis, and that only increased doses of morphine may inhibit it $(12,24)$. Furthermore, the present study demonstrated that morphine significantly promoted the migration of A549 cells, whereas oxycodone inhibited migration. Oxycodone also downregulated the expression levels of UPA and ICAM-1 in A549 cells, whereas morphine upregulated the expression levels of these 
proteins. These findings suggested that oxycodone may be an improved candidate for pain management, as compared with morphine, in the treatment of patients with cancer.

In cancer cells, apoptosis is generally impaired which leads to increased cell proliferation. The p53 gene has a directly negative regulatory effect on the promoters of some cell proliferation-related genes, and thus has a vital role in the regulation of apoptosis. Bcl-2 and Bax belong to the Bcl-2 family and the mechanism by which Bcl-2 inhibits apoptosis may be related to its antagonistic effects on the apoptosis-promoting Bax gene (25-27). The results of the present study demonstrated that morphine and oxycodone upregulated the mRNA expression levels of p53 and Bax, and downregulated the Bcl-2 mRNA expression levels in A549 cells, thus suggesting that morphine and oxycodone may promote apoptosis in these cells. At concentrations $>20 \mu \mathrm{g} / \mathrm{ml}$, oxycodone and morphine were able to significantly increase apoptosis in this cell line. Another major characteristic of cancer cells is their ability to migrate into surrounding and distant tissues, which, according to the findings of the present study, may be more preferably suppressed by oxycodone in A549 lung cancer cells, as compared with morphine treatment.

In conclusion, the results of the present study demonstrated that oxycodone and morphine are capable of inducing apoptosis and inhibiting the proliferation of A549 lung cancer cells. In addition, oxycodone, but not morphine, exhibited prominent anti-migration effects in these cells. Taken together, these findings support favorable anti-cancer properties of oxycodone over morphine. Future in vivo studies are required in order to further characterize the anti-malignant potential of oxycodone.

\section{Acknowledgements}

The present study was supported by the National Natural Science Foundation of China (grant nos. 81271216, 81300946) and the Natural Science Foundation of Jiangsu Province (grant no. BK2012778) attributed to the Department of Anesthesiology, Jinling Hospital, School of Medicine, Nanjing University (Nanjing, China).

\section{References}

1. Siegel R, Naishadham D and Jemal A: Cancer statistics, 2012. CA Cancer J Clin 62: 10-29, 2012.

2. Liang H, Gu M, Yang C, Wang H, Wen X and Zhou Q: Sevoflurane inhibits invasion and migration of lung cancer cells by inactivating the p38 MAPK signaling pathway. J Anesth 26: 381-392, 2012.

3. Snyder GL and Greenberg S: Effect of anaesthetic technique and other perioperative factors on cancer recurrence. $\mathrm{Br}$ J Anaesth 105: 106-15, 2010.

4. Afsharimani B, Cabot P and Parat MO: Morphine and tumor growth and metastasis. Cancer Metastasis Rev 30: 225-238, 2011.

5. Cata JP, Bauer M, Sokari T, Ramirez MF, Mason D, Plautz G and Kurz A: Effects of surgery, general anesthesia, and perioperative epidural analgesia on the immune function of patients with non-small cell lung cancer. J Clin Anesth 25: 255-262, 2013.

6. Koodie L, Yuan H,Pumper JA, Yu H, Charboneau R, Ramkrishnan S and Roy S: Morphine inhibits migration of tumor-infiltrating leukocytes and suppresses angiogenesis associated with tumor growth in mice. Am J Pathol 184: 1073-1084, 2014.

7. Boland JW, Foulds GA, Ahmedzai SH and Pockley AG: A preliminary evaluation of the effects of opioids on innate and adaptive human in vitro immune function. BMJ Support Palliat Care 4: 357-367, 2014
8. Suzuki M, Sakurada T, Gotoh K, Watanabe S and Satoh N: Correlation between the administration of morphine or oxycodone and the development of infections in patients with cancer pain. Am J Hosp Palliat Care 30: 712-716, 2013.

9. Welden B, Gates G, Mallari R and Garrett N: Effects of anesthetics and analgesics on natural killer cell activity. AANA J 77: 287-292, 2009.

10. Nguyen J, Luk K, Vang D, Soto W, Vincent L, Robiner S, Saavedra R, Li Y, Gupta P and Gupta K: Morphine stimulates cancer progression and mast cell activation and impairs survival in transgenic mice with breast cancer. Br J Anaesth 113 (Suppl 1): i4-i13, 2014.

11. Roy S, Balasubramanian S, Sumandeep S, Charboneau R, Wang J, Melnyk D, Beilman GJ, Vatassery R and Barke RA: Morphine directs $\mathrm{T}$ cells toward $\mathrm{T}(\mathrm{H} 2)$ differentiation. Surgery 130: 304-309, 2001.

12. Gupta K, Kshirsagar S, Chang L, Schwartz R, Law PY, Yee D and Hebbel RP: Morphine stimulates angiogenesis by activating proangiogenic and survival-promoting signaling and promotes breast tumor growth. Cancer Res 62: 4491-4498, 2002.

13. Biki B, Mascha E, Moriarty DC, Fitzpatrick JM, Sessler DI and Buggy DJ: Anesthetic technique for radical prostatectomy surgery affects cancer recurrence: A retrospective analysis. Anesthesiology 109: 180-187, 2008.

14. Mantyh PW: Cancer pain and its impact on diagnosis, survival and quality of life. Nat Rev Neurosci 7: 797-809, 2006.

15. Ordóñez Gallego A, González Barón M and Espinosa Arranz E: Oxycodone: A pharmacological and clinical review. Clin Transl Oncol 9: 298-307, 2007.

16. Nakamura A, Hasegawa M, Minami K, Kanbara T, Tomii T, Nishiyori A, Narita M, Suzuki T and Kato A: Differential activation of the $\mu$-opioid receptor by oxycodone and morphine in pain-related brain regions in a bone cancer pain model. $\mathrm{Br}$ J Pharmacol 168: 375-388, 2013.

17. Fodale V, D'Arrigo MG, Triolo S, Mondello S and La Torre D: Anesthetic techniques and cancer recurrence after surgery. ScientificWorldJournal 2014: 328513, 2014.

18. Mathew B, Lennon FE, Siegler J, Mirzapoiazova T, Mambetsariev N, Sammani S, Gerhold LM, LaRiviere PJ, Chen CT, Garcia JG, et al : The novel role of the mu opioid receptor in lung cancer progression: A laboratory investigation. Anesth Analg 112: 558-567, 2011.

19. Lennon FE, Mirzapoiazova T, Mambetsariev B, Salgia R, Moss J and Singleton PA: Overexpression of the $\mu$-opioid receptor in human non-small cell lung cancer promotes Akt and mTOR activation, tumor growth, and metastasis. Anesthesiology 116: 857-867, 2012.

20. Kharmate G, Rajput PS, Lin YC and Kumar U: Inhibition of tumor promoting signals by activation of SSTR2 and opioid receptors in human breast cancer cells. Cancer Cell Int 13: 93, 2013.

21. Lin X, Wang YJ, Li Q, Hou YY, Hong MH, Cao YL, Chi ZQ and Liu JG: Chronic high-dose morphine treatment promotes SH-SY5Y cell apoptosis via c-Jun N-terminal kinase-mediated activation of mitochondria-dependent pathway. FEBS J 276: 2022-2036, 2009.

22. Finley MJ, Happel CM, Kaminsky DE and Rogers TJ: Opioid and nociception receptors regulate cytokine and cytokine receptor expression. Cell Immunol 252: 146-154, 2008.

23. Hsiao PN, Chang MC, Cheng WF, Chen CA, Lin HW, Hsieh CY and Sun WZ: Morphine induces apoptosis of human endothelial cells through nitric oxide and reactive oxygen species pathways. Toxicology 256: 83-91, 2009.

24. Koodie L, Ramakrishnan S and Roy S: Morphine suppresses tumor angiogenesis through a HIF-1alpha/p38MAPK pathway. Am J Pathol 177: 984-997, 2010.

25. Suzuki S, Chuang LF, Doi RH and Chuang RY: Morphine suppresses lymphocyte apoptosis by blocking p53-mediated death signaling. Biochem Biophys Res Commun 308: 802-808, 2003.

26. Singhal PC, Bhaskaran M, Patel J, Patel K, Kasinath BS, Duraisamy S, Franki N, Reddy K and Kapasi AA: Role of p38 mitogen-activated protein kinase phosphorylation and Fas-Fas ligand interaction in morphine-induced macrophage apoptosis. J Immunol 168: 4025-4033, 2002.

27. Cory S, Huang DC and Adams JM: The Bcl-2 family: Roles in cell survival and oncogenesis. Oncogene 22: 8590-8607, 2003. 